\title{
Complete revascularisation in STEMI: consider the benefits but do not forget the risks!
}

\author{
Andreas Mitsis ${ }^{\#}$, Alessandro Spirito ${ }^{\#}$, Marco Valgimigli \\ Department of Cardiology, Swiss Cardiovascular Centre, Bern University Hospital, Bern, Switzerland \\ \#These authors contribute equally to this work. \\ Correspondence to: Prof Marco Valgimigli, MD, PhD. Swiss Cardiovascular Centre Bern, Bern University Hospital, University of Bern, Freiburgstrasse \\ 4, 3010, Bern, Switzerland. Email: marco.valgimigli@insel.ch. \\ Provenance: This is an invited article commissioned by the Guest Section Editor Dr. Yue Liu (Department of Cardiology, The First Affiliated Hospital \\ of Harbin Medical University, Harbin, China). \\ Comment on: Kyhl K, Ahtarovski KA, Nepper-Christensen L, et al. Complete Revascularization Versus Culprit Lesion Only in Patients With ST- \\ Segment Elevation Myocardial Infarction and Multivessel Disease: A DANAMI-3-PRIMULTI Cardiac Magnetic Resonance Substudy. JACC \\ Cardiovasc Interv 2019;12:721-30.
}

Submitted Aug 11, 2019. Accepted for publication Sep 20, 2019

doi: 10.21037/atm.2019.09.121

View this article at: http://dx.doi.org/10.21037/atm.2019.09.121

Multivessel disease is a common scenario in ST elevation myocardial infraction (STEMI) patients and up to $50 \%$ of them may have additional angiographically severe lesions in non-culprit coronaries $(1,2)$. Patients with extensive disease in vessels other than the infract related artery (IRA) are known to have inferior prognosis compared with the patients with single-vessel disease $(3,4)$. While the benefits of treating the culprit artery and restoring coronary flow have been extensively and conclusively documented, the evidence of whether to treat other angiographically significant lesions in asymptotic patients outside the IRA or not is less convincing. Indeed, it may be argued that complete revascularisation of significant non-IRA might prevent recurrent ischaemia and adverse cardiac events, while a common counterargument is that this approach might cause periprocedural myocardial infarction (MI) potentially leading to larger infract size and worst prognosis.

Four major randomised trials have tried to assess the risks and benefits of complete versus incomplete revascularisation in STEMI patients undergoing primary PCI (Table 1). Preventive angioplasty in acute myocardial infarction (PRAMI) trial assigned 465 multivessel disease patients to undergo either preventive PCI (234 patients) or no preventive PCI (231 patients). At an average follow-up of 23 months, preventive PCI in the non-IRA with stenosis $\geq 50 \%$ (i.e., based on lumen narrowing assessed at the time of index angiogram) was associated with lower rates of the compound primary endpoint of death, myocardial infraction, or refractory angina (9\% versus $23 \%$ ) (HR 0.35 , 95\% CI: $0.21-0.58 ; \quad \mathrm{P}<0.001)(5)$. Notably, this is the only study, which observed a strong trend towards a possible mortality benefit in patients who underwent angiographybased complete revascularisation and a significant reduction of recurrent MI.

In complete versus lesion-only PRimary PCI pilot study (CvLPRIT) trial, 296 patients have been assigned to either complete revascularisation $(\mathrm{n}=150)$ or culprit lesion only primary PCI $(n=146)$. The timing of complete revascularization was after the primary PCI (P-PCI) or during the same hospital stay and as in PRAMI the decision to revascularise or not the non-culprit lesions was based on angiography. The primary endpoint was a compound of death, recurrent MI, heart failure, and ischemia-driven revascularization. The complete revascularisation group was associated with lower rates of the primary endpoint within a 12 -month period (10.0 \% versus $21.2 \%$ ) (HR 0.45, 95\% CI: 0.24-0.84; $\mathrm{P}=0.009)$ (6). In this study, the benefit of complete revascularisation was apparently driven by each component of the primary endpoint being numerically even if not statistically significant lower in the experimental group.

The third Danish study of primary PCI in patients with ST-elevation MI and multivessel disease: treatment of culprit lesion only or complete revascularization 
(DANAMI-3-PRIMULTI) was the third randomised study to become available. In this study, 627 patients were assigned to only IRA-only revascularisation or FFRguided complete revascularisation. The primary endpoint at a mean follow up of 27 months, was a compound of allcause mortality, non-fatal myocardial re-infarction, and ischaemia-driven revascularization of lesions other than the IRA artery and occurred in 68 (22\%) patients who had IRA PCI only and in $40(13 \%)$ patients who had complete revascularization (HR 0.56, 95\% CI: 0.38-0.83; $\mathrm{P}=0.004$ ). This advantage was driven mainly by a reduction in repeat revascularization (7), without a cleat impact on mortality or MI rates.

Finally, the Fractional Flow Reserve-Guided Multivessel Angioplasty in Myocardial Infarction (Compare-Acute) trial enrolled 885 patients with STEMI and multivessel disease to FFR-guided complete revascularisation or culprit lesion only treatment. A reduction of the primary endpoint (death, MI, revascularization, or stroke) was observed with multivessel PCI (HR 0.35, 95\% CI: 0.22-0.55; P<0.001), which was driven mainly by a reduction in the need for revascularization at a later time point by non-IRA FFRguided revascularization (8).

A recent meta-analysis of 10 trials (but not included the Compare-Acute study) demonstrated that complete revascularization was related with a lower risk of MACE (RR 0.57, 95\% CI: 0.42-0.77). This benefit was driven by a lower risk of urgent revascularization (RR $0.44,95 \%$ CI: $0.30-0.66)$, while there was no significant difference in mortality (RR $0.76,95 \%$ CI: $0.52-1.12$ ) or spontaneous MI (RR 0.54, 95\% CI: 0.23-1.27) (9).

The recent 2018 ESC/EACTS Guidelines on myocardial revascularization (10) recommend that routine complete revascularization should be considered in patients with multivessel disease during the same hospital stay (Class IIA, Level of evidence A). Similarly, the 2015 ACC/AHA/SCAI recommendations (11), suggest that non-IRA PCI may be considered in selected hemodynamically stable patients with STEMI and multivessel disease, either during primary PCI or as a staged procedure.

Whether complete revascularisation after STEMI in multivessel disease patients improves LV function and volumes remains unclear. In addition, the risks of inducing peri-procedural MI when attempting at completing revascularisation has not been well documented so far.

The recent publication of the Cardiac Magnetic Resonance Sub-study of the DANAMI-3-PRIMULTI (12) adds new pieces of the puzzle, which, however, does not yet come together. A non-randomly selected group of 280 patients (136 patients with IRA PCI and 144 with complete FFR-guided revascularization) underwent CMR before receiving (or not receiving) complete revascularisation and at 3 months. The final infract size, myocardial salvage index, LV ejection fraction (LVEF) and LV end-systolic volume (LVESV) remodelling were similar between the two groups. Interestingly, new non-culprit infarctions were numerically more common in the complete revascularization group [6 (4.5\%) versus $1(0.8 \%) ; \mathrm{P}=0.12$ ]. Therefore, this study may actually suggest that the risks of complete revascularisation, in terms of peri-procedural MI, may outweigh or at least counterbalance its possible benefit on LV function and volumes.

However, one may argue that three month-time frames is rather short to allow detecting significant different in LV remodelling. No proper sample size calculation was performed to justify the number of included patients; therefore, study power remains an issue. Moreover, whether FFR or angiography should be used to guide compete revascularisation is still unclear. In the early stage of acute MI, disturbed microvascular function might affect the reliability of FFR measurements. Microvascular dysfunction in the culprit territory is quite often due to distal thrombus embolization and vasoconstriction. This may lead to impaired hyperaemic flow in the non-culprit myocardium, possibly leading to underestimation of real FFR values in the acute setting. Studies using positronemission tomography and Doppler flow have tested this hypothesis and presumed that during MI the non-infarcted myocardium is also affected $(13,14)$. However, other studies suggest that FFR measurements in non-culprit vessels of patients with myocardial infraction are consistent and therefore FFR may be used to guide revascularization in the acute setting of a STEMI $(15,16)$.

Prior to the DANAMI-3-PRIMULTI Cardiac Magnetic Resonance Sub-study, two similar sub-studies have been designed in order to assess the impact of multivessel PCI in LV parameters, using CMR (Table 2). In the CvLPRIT CMR sub-study, 203 patients (98 complete revascularization and 105 IRA-only) evaluated with CMR. There was no difference in the total median infarct size between the two groups. Notably, there were more non-IRA MIs in the complete revascularization group (22 of 98 versus 11 of 105; $\mathrm{P}=0.02)$ and also in this study there was no detectable effect of complete revascularisation on infarct size or $\mathrm{LV}$ volumes (17). 84 patients have been investigated with CMR within the PRAMI Trial (18). Consistently with 


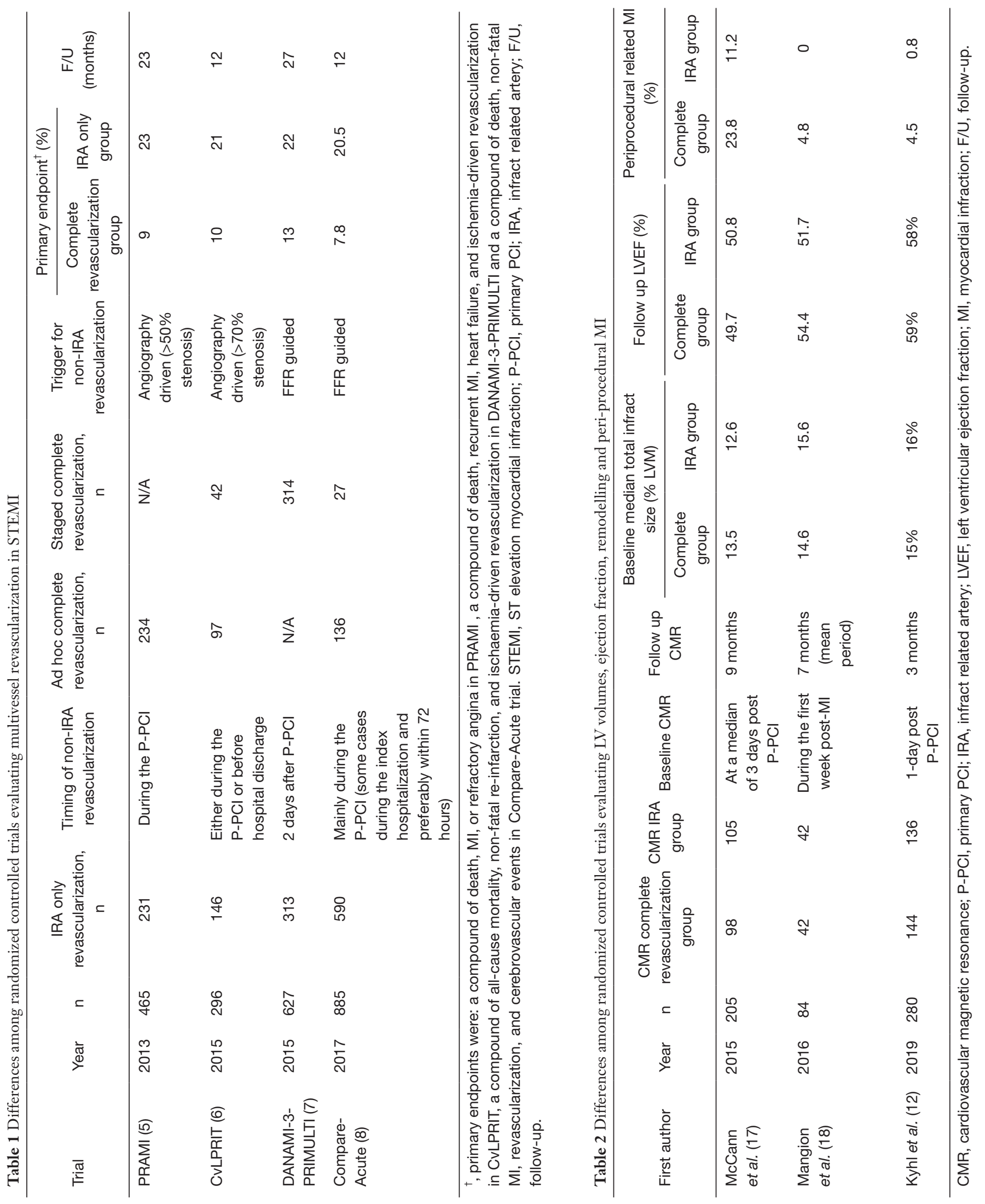


other evidence, the infarct size (\% LV mass) at baseline and follow-up did not differ in the two study groups. However, in this study the incidence of peri-procedural MI in the preventive PCI group was uncommon (4.8\%), may reflect the patient selection more than the real risks of competing revascularisation in an unselected patient population.

Therefore, no single study has so far shown an effect of complete revascularisation in STEMI patients on LV mechanics or remodelling whereas all studies have shown a sizable, yet variable, risk of peri-procedural MI. The prognostic implication of clinically silent CMR-detected $\mathrm{MI}$ is unclear. Yet, the benefit of complete revascularization in patients with STEMI and multivessel disease should be counterbalanced against a coexisting risk for periprocedural myocardial infraction.

\section{Acknowledgments}

None.

\section{Footnote}

Conflicts of Interest: The following relationships outside the submitted work are disclosed by the authors: Marco Valgimigli reports personal fees from Astra Zeneca, grants and personal fees from Terumo, personal fees from Alvimedica/CID, personal fees from Abbott Vascular, personal fees from Daiichi Sankyo, personal fees from Opsens, personal fees from Bayer, personal fees from CoreFLOW, personal fees from IDORSIA PHARMACEUTICALS LTD, personal fees from Universität Basel I Dept. Klinische Forschung, personal fees from Vifor, personal fees from Bristol Myers Squib SA, personal fees from iVascular. Andreas Mitsis has received a training grant from Medtronik. Alessandro Spirito has no conflicts of interest to declare.

Ethical Statement: The authors are accountable for all aspects of the work in ensuring that questions related to the accuracy or integrity of any part of the work are appropriately investigated and resolved.

\section{References}

1. Park DW, Clare RM, Schulte PJ, et al. Extent, location, and clinical significance of non-infarct-related coronary artery disease among patients with ST-elevation myocardial infarction. JAMA 2014;312:2019-27.
2. Dziewierz A, Siudak Z, Rakowski T, et al. Impact of multivessel coronary artery disease and noninfarctrelated artery revascularization on outcome of patients with ST-elevation myocardial infarction transferred for primary percutaneous coronary intervention (from the EUROTRANSFER Registry). Am J Cardiol 2010;106:342-7.

3. Halkin A, Singh M, Nikolsky E, et al. Prediction of mortality after primary percutaneous coronary intervention for acute myocardial infarction: the CADILLAC risk score. J Am Coll Cardiol 2005;45:1397-405.

4. Sorajja P, Gersh BJ, Cox DA, et al. Impact of multivessel disease on reperfusion success and clinical outcomes in patients undergoing primary percutaneous coronary intervention for acute myocardial infarction. Eur Heart J 2007;28:1709-16.

5. Wald DS, Morris JK, Wald NJ, et al. PRAMI Investigators. Randomized trial of preventive angioplasty in myocardial infarction. N Engl J Med 2013;369:1115-23.

6. Gershlick AH, Khan JN, Kelly DJ, et al. Randomized trial of complete versus lesion-only revascularization in patients undergoing primary percutaneous coronary intervention for STEMI and multivessel disease: the CvLPRIT trial. J Am Coll Cardiol 2015;65:963-72.

7. Engstrøm T, Kelbaek H, Helqvist S, et al. Complete revascularisation versus treatment of the culprit lesion only in patients with ST-segment elevation myocardial infarction and multivessel disease (DANAMI-3PRIMULTI): an open-label, randomised controlled trial. Lancet 2015;386:665-71.

8. Smits PC, Abdel-Wahab M, Neumann FJ, et al. CompareAcute Investigators. Fractional flow reserve-guided multivessel angioplasty in myocardial infarction. $\mathrm{N}$ Engl J Med 2017;376:1234-44.

9. Elgendy IY, Mahmoud AN, Kumbhani DJ, et al. Complete or culprit-only revascularization for patients with multivessel coronary artery disease undergoing percutaneous coronary intervention: A pairwise and network meta-analysis of randomized trials. JACC Cardiovasc Interv 2017;10:315-24.

10. Neumann FJ, Sousa-Uva M, Ahlsson A, et al. 2018 ESC/ EACTS guidelines on myocardial revascularization. Eur Heart J 2019;40:87-165.

11. Levine GN, Bates ER, Blankenship JC, et al. 2015 ACC/ AHA/SCAI focused update on primary percutaneous coronary intervention for patients with ST-elevation myocardial infarction: an update of the 2011 ACCF/AHA/ SCAI guideline for percutaneous coronary intervention 
and the 2013 ACCF/AHA guideline for the management of ST-elevation myocardial infarction. J Am Coll Cardiol 2016;67:1235-50.

12. Kyhl K, Ahtarovski KA, Nepper-Christensen L, et al. Complete Revascularization Versus Culprit Lesion Only in Patients With ST-Segment Elevation Myocardial Infarction and Multivessel Disease: A DANAMI-3PRIMULTI Cardiac Magnetic Resonance Substudy. JACC Cardiovasc Interv 2019;12:721-30.

13. Uren NG, Crake T, Lefroy DC, et al. Reduced coronary vasodilator function in infarcted and normal myocardium after myocardial infarction. N Engl J Med 1994;331:222-7.

14. de Waard GA, Hollander MR, Teunissen PF, et al. Changes in coronary blood flow after acute myocardial infarction: insights from a patient study and an experimental porcine model. JACC Cardiovasc Interv 2016;9:602-13.

Cite this article as: Mitsis A, Spirito A, Valgimigli M. Complete revascularisation in STEMI: consider the benefits but do not forget the risks! Ann Transl Med 2019;7(Suppl 8):S331. doi: 10.21037/atm.2019.09.121
15. Ntalianis A, Sels JW, Davidavicius G, et al. Fractional flow reserve for the assessment of nonculprit coronary artery stenoses in patients with acute myocardial infarction. JACC Cardiovasc Interv 2010;3:1274-81.

16. Lee JM, Kim HK, Lim KS, et al. Influence of local myocardial damage on index of microcirculatory resistance and fractional flow reserve in target and nontarget vascular territories in a porcine microvascular injury model. JACC Cardiovasc Interv 2018;11:717-24.

17. McCann GP, Khan JN, Greenwood JP, et al. Complete versus lesion-only primary PCI: the randomized cardiovascular MR CvLPRIT substudy. J Am Coll Cardiol 2015;66:2713-24.

18. Mangion K, Carrick D, Hennigan BW, et al. Infarct size and left ventricular remodelling after preventive percutaneous coronary intervention. Heart 2016;102:1980-7. 